\title{
Changes in Arthropod Fauna From Weed Management Practices in Genetically Modified Herbicide-Tolerant Maize
}

\author{
Ramon Albajes ${ }^{1}$, Belén Lumbierres ${ }^{1}$, Xavier Pons ${ }^{1} \&$ Jordi Comas ${ }^{2}$ \\ ${ }^{1}$ Universitat de Lleida, Agrotecnio Center, Lleida, Spain \\ ${ }^{2}$ Universitat Politècnica de Catalunya, Departament d'Enginyeria Agroalimentària i Biotecnologia, Barcelona, \\ Spain \\ Correspondence: Ramon Albajes, Universitat de Lleida, Agrotecnio Center, Rovira Roure 191, Lleida 25198, \\ Spain. Tel: 349-7370-2571. E-mail: ramon.albajes@irta.cat
}

Received: June 24, 2014 Accepted: July 28, 2014 Online Published: September 15, 2014

doi:10.5539/jas.v6n10p67 URL: http://dx.doi.org/10.5539/jas.v6n10p67

\begin{abstract}
Genetically modified maize tolerant to broad-spectrum herbicides may greatly alter weed flora composition, abundance and therefore affect organisms of higher trophic levels, including herbivore and detritivore arthropods and their natural enemies. This three-year study measured the effects on arthropods of an intensive use of broad-spectrum herbicides in comparison with one application of conventional pre-emergence herbicide. Numbers of arthropods were measured by three techniques: visual counts on plants, catches in pitfall and yellow sticky traps. Weed density was much higher in conventional treatment in the first year, showed significant difference in the second year, but was no significant difference in the third year. Counts of arthropod taxa were significantly different only in the first year in the two kinds of weed management systems. In visual counts Cicadellidae and Aphididae among herbivores, the two main generalist predators, Orius spp. and Araneae, and the family Coccinellidae were more abundant on plants treated twice with glyphosate. In pitfall there were higher records in glyphosate-treated plots for Myriapoda but the opposite was seen for Carabidae counts. The yellow sticky traps catches were higher in the glyphosate-treated plots for Cicadellidae and Mymaridae, and lower for Thysanoptera. Most of the significant differences found between herbicide regimes disappeared when abundances of weeds (monocotyledons and dicotyledons) were introduced into the analysis as covariates; this finding signals weed abundance as the main cause of arthropod abundance alteration. However, only a drastic alteration of weed abundance causes significant changes in arthropod densities.
\end{abstract}

Keywords: GM crops, GMHT corn, Orius, Araneae, Carabidae, Mymaridae

\section{Introduction}

Genetically modified herbicide-tolerant (GMHT) maize was cultivated in millions of hectares in 2013 (James, 2013). Application of broad-spectrum herbicides may alter the composition and abundance of weed flora and other components at higher trophic levels, among which there are the arthropods (Heard et al., 2003). These provide important services in agrosystems like pollination, biological control, nutrient cycling and provision of resources for other organisms that might be interfered by drastic changes in weed management practices (Norris \& Kogan, 2000). The general goal of weed management is to lower the competition of weeds with the crop plant and thus reduce crop yield losses as much as possible. Weeds are thus regarded and managed as mere competitors of the crop plant, particularly in maize, which is very susceptible to early weed competition (Bradley et al., 2000). However, weeds may play other roles in agrosystems and influence higher trophic levels, such as arthropod herbivores and their natural enemies, and any alteration in the numbers, composition or phenology of weed communities may be transferred to the whole food web through several mechanisms (Smith et al., 2008).

Effects of GMHT crops on arthropods may be a direct result of the toxic effect of broad-spectrum herbicides or the deleterious consequences of the transgenic trait or its products. However, they may also be mediated indirectly via plant food resources or habitat modification (Marshall et al., 2001). No records of direct harmful effects of the GMHT trait on arthropods have been reported. Lethal and sublethal effects of broad-spectrum herbicides on natural enemies have been recorded rarely in the case of glyphosate (Franz et al., 1997; Michalková \& Pekár, 2009; Schneider et al., 2009; Evans et al., 2010) and glufosinate (Ahn et al., 2001), but most of them have been studied only in the laboratory and sometimes at high concentrations (Marshall et al., 
2001).

The indirect effects of GMHT crops on the interactions between weeds and arthropods are difficult to study owing to their complexity and the lack of an ecological theory that would explain arthropod responses to vegetation changes in agrosystems. Arthropod-weed interactions have been dealt with in the review by Norris and Kogan (2000), the analysis of the compatibility of GMHT crops and biological control by Lundgren et al. (2009) and the study of the influence of weed control and crop management practices on invertebrates by Smith et al. (2008). However, little generalization has been provided in this field by plant and insect ecologists. Much of the ecological thinking on weed and arthropod relationships was formulated by Andow (1991), who hypothesized that more herbivores and fewer natural enemies may be expected in weed-free plots than in polycultures. Altieri (1999) stated that weedy plots lead to higher numbers of predators but his conclusion was backed by relatively little experimental support. On the contrary, it has been reported that a lower abundance of weeds leads to higher predator numbers in maize, as in the case of the coccinellid beetle Coleomegilla maculata De Geer (Andow \& Risch, 1985) and the general predators Orius spp. and spiders (Albajes et al., 2009). Finally, other studies (Penagos et al., 2003; Gianoli et al., 2006) found no differences in the numbers of on-plant predators between weedy and non-weedy corn plots.

The complexity of weed-arthropod relationships in agrosystems and the difficulty of predicting the changes in food webs resulting from the deployment of GMHT crops were demonstrated in the UK in the Farm Scale Evaluations. These large field trials were designed to compare the impacts of weed management on the diversity of plants and arthropods in GMHT and conventional crops. For three years more than 60 half-fields of beet, maize and spring oilseed rape were treated with broad-spectrum herbicides vs. conventional herbicides and the effects of the two weed management systems on plants and soil-surface-active invertebrates (Brooks et al., 2003), aerial and epigeal arthropods (Haughton et al., 2003) and invertebrates in field margins (Roy et al., 2003) were assessed. Differences in arthropod abundances varied during the season and between seasons, crops and taxa. As stated by Hawes et al. (2003), the introduction of new herbicide regimes will likely affect weed communities and many arthropods that are sensitive to weed community changes. However, no general pattern in the direction of these changes was found over the three years of the Farm Scale Evaluations, despite the high number of fields (about 200) and organisms (more than 100) assessed. In maize the biomass of weeds was greater in GMHT crops than in crops treated with conventional herbicide, whereas in beet and oilseed rape fields the biomass of weeds was lower in GMHT crops. The greater abundance of weeds in GMHT maize coincided with higher counts of several of the taxa recorded on plants and on the soil (Brooks et al., 2003; Haughton et al., 2003).

A better understanding of the weed-arthropod relationships would allow a better prediction of potential alterations of agrosystem food webs by GMHT crops and would open the possibility of managing broad-spectrum herbicide timing to both limit weed competition for the crop plants and to enhance benefits of weed presence for the biological control functions exerted by predators and parasitoids (Dewar, 2009; Bigler \& Albajes, 2011). In a previous step of a multi-year field trial to assess environmental risks of GMHT maize for herbivore, predatory, parasitic and decomposer arthropods, Albajes et al. (2009) found that several taxa responded to different abundances of weeds when untreated maize plots were compared with plots treated twice with a broad-spectrum herbicide (glyphosate). Whereas counts of some herbivores, predators and parasitoids were higher in GMHT treatment, for other taxa the contrary was found.

This study aimed to analyse the response of the most responsive arthropod taxa found by Albajes et al. (2009) to different weed flora abundances resulting from two herbicide regimes, one with two treatments with glyphosate per season and the other with one conventional pre-emergence herbicide treatment. To this end, a three-year field trial with the two treatments was performed and the most abundant arthropod taxa were recorded by visual counts, pitfall traps and yellow sticky traps.

\section{Materials and Methods}

\subsection{Study Area and Cultural Practices}

A three-year field trial was conducted in the Lleida area (NE Spain, $41.36^{\circ} \mathrm{N}, 0.36^{\circ} \mathrm{E}, 223$ masl). In the study area maize is commonly grown within a rotation including alfalfa and a winter cereal. The experimental field was surrounded by winter cereals and alfalfa with a $1.5-\mathrm{m}$ margin between them, and no other corn field was within a radius of $300 \mathrm{~m}$ according to the Spanish legislation on cultivation of non-commercial GM crops for experimental purposes. The crop in the experimental field prior to sowing maize was alfalfa. Weeds were removed by tillage just before sowing and no insecticide treatment was applied except to seeds, which were dressed with the insecticide Imidacloprid. The field was irrigated using sprinklers, and the cultural practices were 
the common ones in the region with the exception of glyphosate treatment.

\subsection{Experimental Design and Herbicide Treatments}

The herbicide treatments consisted of (i) two applications of glyphosate at V4 and V8 corn growth stages at a rate of $1.08 \mathrm{~kg}(\mathrm{AI}) / \mathrm{ha}$ (called the 'glyphosate treatment' from here onwards) and (ii) a conventional pre-emergence treatment with a mixture of $1.4 \mathrm{~kg} / \mathrm{ha}$ alachlor and $0.8 \mathrm{~kg} / \mathrm{ha}$ atrazine (Alclor complex ${ }^{\circledR}$ Alcotan, Spain, $4 \mathrm{l} / \mathrm{ha}$ ) in the first year, and a mixture of $1.26 \mathrm{~kg} / \mathrm{ha}$ acetochlor (Harness ${ }^{\circledR}$ Plus Monsanto, Spain, $1.5 \mathrm{l} / \mathrm{ha}$ ) and $0.5 \mathrm{~kg} / \mathrm{ha}$ aclonifen mixed with $0.075 \mathrm{~kg} / \mathrm{ha}$ isoxaflutol (Lagon ${ }^{\circledR}$, Bayer, Spain, 1 1/ha) in the second and third year (called the 'conventional treatment' from here onwards). The plot treated with a conventional herbicide had not been treated with herbicides in the year before the start of the study and therefore had a higher number of weeds than usual in maize fields. A complete four-random-block design was used. Treatments were randomly assigned to each block in the first year, but randomization was not used in the second and third years because treatments were repeated on the same plot. Experimental units were plots of 0.5 ha in size. The whole experimental field was sown in the fourth week of April in the three years with the same variety (TEB652-E), including the transformation event NK603, which confers tolerance to over-the-top applications with glyphosate herbicide. Weeds from rows between experimental plots were removed by tillage or, when needed, by hand.

\subsection{Sampling}

Results of weed counts were provided by weed scientists in INIA. Abundance of weeds per square metre was estimated by counting the number of individuals within a $0.25-\mathrm{m}^{2}$ ring; on each plot, rings were randomly distributed 16 times on each principal diagonal. Weeds were identified to genus level and, when possible, to species level. Counts were carried out just before herbicide application and 10 to $15 \mathrm{~d}$ after the last herbicide treatment. Here only the total number of monocotyledons and dicotyledons after the last herbicide treatment is given.

Three techniques were used to estimate arthropod densities or activities: visual counting, pitfall traps, and yellow sticky traps. Samples were taken seven times per season with each of the techniques at the following corn growth stages: V6-7, V8-10, V12-14, V14-15, R1, R3 and R5 (nomenclature of Ritchie et al., 1992). On each sampling date the number of crop plant-dwelling herbivores and predators was visually counted on 25 plants per plot early in the morning, when the insects were less active. Individuals were identified to different taxon levels. Among herbivores, three main groups were recorded: leafhoppers and aphids were identified to species level and thrips to order level. The whorl leaves were carefully inspected to count the number of thrips on the first two sampling dates and from the third sampling date onward only thrips on leaves and stalk were counted. Among the predators, Araneae and predatory Thysanoptera were recorded as whole groups; trombidiids, staphylinids, and syrphids were recorded to family level; and anthocorids, nabids, mirids, chrysopids, carabids and coccinellids were identified to genus or species level.

Three pitfall traps (glass jars $8 \mathrm{~cm}$ wide by $17 \mathrm{~cm}$ high half-filled with water and $20 \%$ ethylene-glycol) were arranged on each plot, regularly distributed along the plot length but at least $10 \mathrm{~m}$ from the field border, and left active for 5 days on each sampling date. They were protected from irrigation sprinklers by a $25-$ by $17.5-\mathrm{cm}^{2}$ roof placed at $3 \mathrm{~cm}$ height from the ground. The individuals caught were taken to the laboratory, kept in the refrigerator until they could be processed, and identified to taxon level. Araneae and the sum of millipedes and centipedes (Myriapoda) were recorded as whole groups. Collembola were divided into two groups: globular and elongate. Staphylinids (adults and larvae) were identified to family level, and earwigs and the most abundant carabid adults were identified to genus or species level.

Three yellow sticky traps (21 by $31 \mathrm{~cm}$, only one sticky side; Serbios, Badia Polesine, Italy) per plot were put on a stake at canopy height (until V12) or at ear level (from V15 onward) and left active for 5 days. They were taken to the laboratory and kept in the refrigerator until they were identified to taxon level. The herbivores recorded were aphids, leafhoppers, planthoppers and thrips. Among predators, the number of individuals belonging to the following taxonomic levels was counted: Orius spp. Nabis spp., other Heteroptera, thrips, chrysopids, staphylinids, and species of coccinellids. Parasitoids caught belonged to the families of Ichneumonidae and Braconidae or to the superfamily Chalcidoids, among which the family Mymaridae were recorded separately because of their particularly high numbers. Finally, the number of individuals of two heterogeneous groups of chloropids and muscid plus tachinid flies were also recorded. Voucher specimens of the main arthropods identified were deposited in the Laboratory of Entomology (University of Lleida, Lleida, Spain). 


\subsection{Statistical Analysis}

Arthropod abundance and captures were expressed as mean season values, i.e. all sampling dates were confounded. Sampling date was therefore not introduced into the analysis, so the potential problem of lack of independence of longitudinal samples was avoided (Comas et al., 2013). Before analysis seasonal means were transformed by $\log _{10}(x+1)$ to normalize the variable analysed, following EFSA recommendations for this type of field data (EFSA, 2010). The contrast of differences between treatment means was performed within each year for both weed and arthropod density. For arthropods the analysis was performed by first considering only the treatment (one-way ANOVA) and then introducing the abundance of monocotyledonous and dicotyledonous weeds as covariates (one-way ANCOVA with two covariates). Analysis were performed using the $\operatorname{lm}($ ) and $\operatorname{aov}()$ functions from the package stats developed by the R Core Team (R Development Core Team, 2008).

\section{Results}

\subsection{Weeds}

The abundance of grass, dicotyledons, and total weeds on the two types of plot is given in Table 1. Most grasses (> 90\%) were Echinocloa crusgalli or Setaria spp. and prevalent dicotyledonous species belonged to the genera Amaranthus, Chenopodium, Portulaca, and Abutilon (which together accounted for $63 \%$ of the total dicotyledonous weeds). Differences between the two treatments varied for each year and are shown in Table 1. Monocotyledons were much more abundant in the first year in the conventional herbicide treatment (15 times, $P$ $\leq 0.05$, d.f. $=1,6$ ) probably because these plots had not been treated with herbicides the year before, as mentioned in the Materials and Methods section. This significant difference remained in the second year ( 2 times, $P \leq 0.05$, d.f. $=1,6)$ but not in the third year $(P>0.05$, d.f. $=1,6)$. A rather different pattern was observed for dicotyledonous weeds. Whereas in the first year there were significantly more dicotyledons in the conventional treatment than in the glyphosate treatment $(1.7$ times, $P \leq 0.05, d . f .=1,6)$, but no significant differences were recorded in the other two years $(P>0.05, d . f .=1,6)$ (Table 1$)$.

Table 1. Mean ( \pm S.E.) number of individuals per plant of different arthropod taxa recorded by visual sampling and probabilities in the one-way ANOVA $(d . f .=1,6)$ and one-way ANCOVA when number of monocotyledonous and dicotyledonous weeds were the covariates $(d . f .=1,4)$ (Values of weeds are expressed in mean number per sq.m.)

\begin{tabular}{|c|c|c|c|c|c|c|}
\hline \multirow{2}{*}{ Taxon } & \multicolumn{2}{|c|}{ Herbicide treatment } & \multirow{2}{*}{$\frac{\text { ANOVA }(P)}{\text { Treatment }}$} & \multicolumn{3}{|c|}{$\operatorname{ANCOVA}(P)$} \\
\hline & Conventional & Glyphosate & & Monocotyledons & Dicotyledons & Treatment \\
\hline \multicolumn{7}{|c|}{ Year 1} \\
\hline \multicolumn{7}{|l|}{ Weeds } \\
\hline Monocotyledons & $89.4 \pm 34.60$ & $6.00 \pm 4.30$ & $<0.001$ & - & - & - \\
\hline Dicotyledons & $25.5 \pm 5.50$ & $14.80 \pm 2.80$ & 0.007 & - & - & - \\
\hline \multicolumn{7}{|l|}{ Herbivores } \\
\hline Aphididae & $4.13 \pm 1.78$ & $7.99 \pm 1.80$ & 0.018 & 0.052 & 0.886 & 0.170 \\
\hline Cicadellidae & $24.58 \pm 11.91$ & $65.39 \pm 26.74$ & 0.020 & 0.001 & 0.023 & 0.184 \\
\hline Thysanoptera (herbivores) & $6.46 \pm 1.02$ & $6.23 \pm 0.49$ & 0.745 & 0.791 & 0.086 & 0.230 \\
\hline \multicolumn{7}{|l|}{ Predators } \\
\hline Araneae & $1.23 \pm 0.45$ & $2.59 \pm 0.58$ & 0.015 & 0.019 & 0.931 & 0.033 \\
\hline Trombidiidae & $0.05 \pm 0.03$ & $0.06 \pm 0.04$ & 0.458 & 0.315 & 0.470 & 0.188 \\
\hline Orius spp. & $2.80 \pm 0.17$ & $3.90 \pm 0.40$ & 0.002 & 0.005 & 0.716 & 0.140 \\
\hline Nabis sp. & $0.03 \pm 0.01$ & $0.06 \pm 0.04$ & 0.191 & 0.356 & 0.692 & 0.592 \\
\hline Thysanoptera (predatory) & $0.07 \pm 0.05$ & $0.10 \pm 0.05$ & 0.375 & 0.468 & 0.125 & 0.603 \\
\hline Chrysopidae & $0.12 \pm 0.08$ & $0.14 \pm 0.01$ & 0.372 & 0.455 & 0.613 & 0.327 \\
\hline Carabidae & $0.17 \pm 0.04$ & $0.16 \pm 0.09$ & 0.644 & 0.330 & 0.330 & 0.092 \\
\hline Staphylinidae & $0.30 \pm 0.13$ & $0.27 \pm 0.08$ & 0.826 & 0.965 & 0.720 & 0.545 \\
\hline Coccinellidae & $0.08 \pm 0.02$ & $0.24 \pm 0.09$ & 0.007 & 0.029 & 0.140 & 0.118 \\
\hline
\end{tabular}




\begin{tabular}{|c|c|c|c|c|c|c|}
\hline Syrphidae & $0.07 \pm 0.03$ & $0.08 \pm 0.02$ & 0.478 & 0.237 & 0.773 & 0.199 \\
\hline Total predators & $4.92 \pm 0.56$ & $7.56 \pm 0.89$ & 0.002 & 0.002 & 0.789 & 0.012 \\
\hline \multicolumn{7}{|c|}{ Year 2} \\
\hline \multicolumn{7}{|l|}{ Weeds } \\
\hline Monocotyledons & $12.80 \pm 1.30$ & $6.50 \pm 1.40$ & 0.001 & - & - & - \\
\hline Dicotyledons & $15.40 \pm 7.20$ & $9.90 \pm 2.20$ & 0.215 & - & - & - \\
\hline \multicolumn{7}{|l|}{ Herbivores } \\
\hline Aphididae & $2.95 \pm 0.75$ & $2.28 \pm 0.75$ & 0.073 & 0.31 & 0.110 & 0.103 \\
\hline Cicadellidae & $34.77 \pm 4.19$ & $35.08 \pm 4.09$ & 0.916 & 0.54 & 0.825 & 0.251 \\
\hline Thysanoptera (herbivores) & $10.82 \pm 3.21$ & $9.71 \pm 4.13$ & 0.615 & 0.483 & 0.856 & 0.526 \\
\hline \multicolumn{7}{|l|}{ Predators } \\
\hline Araneae & $1.63 \pm 0.40$ & $1.72 \pm 0.30$ & 0.679 & 0.953 & 0.306 & 0.244 \\
\hline Trombidiidae & $0.01 \pm 0.00$ & $0.01 \pm 0.01$ & - & - & - & - \\
\hline Orius spp. & $2.53 \pm 0.51$ & $2.58 \pm 0.61$ & 0.923 & 0.763 & 0.224 & 0.817 \\
\hline Nabis sp. & $0.06 \pm 0.01$ & $0.04 \pm 0.01$ & 0.286 & 0.527 & 0.059 & 0.036 \\
\hline Thysanoptera (predatory) & $0.10 \pm 0.07$ & $0.18 \pm 0.07$ & 0.445 & 0.331 & 0.819 & 0.533 \\
\hline Chrysopidae & $0.07 \pm 0.04$ & $0.05 \pm 0.02$ & 0.696 & 0.597 & 0.019 & 0.798 \\
\hline Carabidae & $0.39 \pm 0.09$ & $0.40 \pm 0.10$ & 0.839 & 0.709 & 0.500 & 0.746 \\
\hline Staphylinidae & $0.25 \pm 0.06$ & $0.25 \pm 0.06$ & 0.856 & 0.474 & 0.255 & 0.068 \\
\hline Coccinellidae & $0.16 \pm 0.08$ & $0.18 \pm 0.07$ & 0.556 & 0.809 & 0.288 & 0.216 \\
\hline Syrphidae & $0.05 \pm 0.01$ & $0.03 \pm 0.01$ & 0.143 & 0.140 & 0.470 & 0.705 \\
\hline Total predators & $5.27 \pm 0.06$ & $5.35 \pm 0.87$ & 0.873 & 0.881 & 0.202 & 0.723 \\
\hline \multicolumn{7}{|c|}{ Year 3} \\
\hline \multicolumn{7}{|l|}{ Weeds } \\
\hline Monocotyledons & $13.16 \pm 6.22$ & $7.13 \pm 4.87$ & 0.211 & - & - & - \\
\hline Dicotyledons & $9.55 \pm 3.22$ & $16.81 \pm 5.10$ & 0.059 & - & - & - \\
\hline \multicolumn{7}{|l|}{ Herbivores } \\
\hline Aphididae & $10.35 \pm 8.64$ & $5.91 \pm 3.98$ & 0.770 & 0.891 & 0.860 & 0.485 \\
\hline Cicadellidae & $36.14 \pm 25.81$ & $36.86 \pm 16.96$ & 0.626 & 0.805 & 0.934 & 0.880 \\
\hline Thysanoptera (herbivores) & $9.93 \pm 2.93$ & $10.30 \pm 3.45$ & 0.485 & 0.712 & 0.574 & 0.626 \\
\hline \multicolumn{7}{|l|}{ Predators } \\
\hline Araneae & $0.84 \pm 0.14$ & $0.87 \pm 0.19$ & 0.463 & 0.379 & 0.917 & 0.808 \\
\hline Trombidiidae & $0.00 \pm 0.00$ & $0.01 \pm 0.01$ & - & - & - & - \\
\hline Orius spp. & $2.49 \pm 0.40$ & $2.39 \pm 0.44$ & 0.722 & 0.820 & 0.700 & 0.382 \\
\hline Nabis sp. & $0.07 \pm 0.02$ & $0.07 \pm 0.02$ & 0.848 & 0.597 & 0.756 & 0.703 \\
\hline Thysanoptera (predatory) & $0.15 \pm 0.06$ & $0.13 \pm 0.10$ & 0.080 & 0.284 & 0.853 & 0.770 \\
\hline Chrysopidae & $0.30 \pm 0.15$ & $0.24 \pm 0.12$ & 0.618 & 0.986 & 0.874 & 0.627 \\
\hline Carabidae & $0.04 \pm 0.02$ & $0.07 \pm 0.05$ & 0.606 & 0.915 & 0.921 & 0.428 \\
\hline Staphylinidae & $0.57 \pm 0.08$ & $0.66 \pm 0.16$ & 0.411 & 0.156 & 0.411 & 0.618 \\
\hline Coccinellidae & $0.30 \pm 0.20$ & $0.21 \pm 0.13$ & 0.557 & 0.752 & 0.945 & 0.606 \\
\hline Syrphidae & $0.02 \pm 0.02$ & $0.01 \pm 0.01$ & 0.617 & - & - & - \\
\hline Total predators & $4.78 \pm 0.27$ & $4.64 \pm 0.79$ & 0.880 & 0.726 & 0.661 & 0.278 \\
\hline
\end{tabular}

\subsection{Arthropods}

A total of 16,189 predatory individuals were recorded on plants in the study, most of them belonging to the genus 
Orius (49.5\%) or Araneae (26.4\%). The number of herbivore arthropods recorded was 167,053 among which the prevalent groups were Cicadellidae (67.0\%), thrips (18.3\%) and aphids (14.7\%). Among herbivores Cicadellidae and Aphididae varied significantly according to the herbicide regime (Table 1) but these differences were only significant in the first year, when there were 2.7 and 1.9 more Cicadellidae and Aphididae, respectively $(P \leq 0.05$, d.f. $=1,6$ for both taxa), on the glyphosate-treated plots (Table 1). Interestingly, significant differences detected in the ANOVA in these herbivores disappeared when number of monocotyledons and number of dicotyledons were introduced in the analysis as covariates $(P>0.05, d . f .=1,4$, for both taxa). This would mean that abundance of both grass and dicotyledonous weeds is a major cause in the influence of the herbicide regime on numbers of Cicadellidae and Aphididae. Among predators, three taxa were affected by the herbicide regime, Orius spp. Araneae, and Coccinellidae, which showed significantly higher counts in the glyphosate treatment but only in the first year $(P \leq 0.05, d . f$. $=1,6$ for the three taxa) (Table 1). As mentioned for Cicadellidae and Aphididae, Orius spp. and Coccinellidae, differences between the two herbicide treatments became insignificant

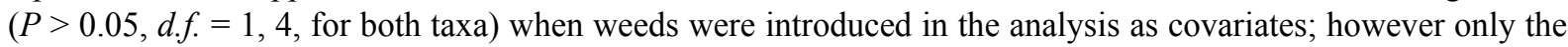
number of monocotyledons was significant $(P \leq 0.05, d . f .=1,4$, for both taxa). In the case of Araneae, differences between treatments remained significant in the analysis of covariance but at a lower significance level and only monocotyledons were significant $(P \leq 0.05, d . f .=1,4)$. Therefore, it seems that Araneae are more abundant on plants of glyphosate-treated plots owing to other causes in addition to the abundance of weeds. A similar pattern was also recorded in the total number of predators. The other two phytophagous and eight predatory taxa were not affected by the herbicide regime in any of the years.

A total of 2,244 predators were caught in pitfall traps and most of them belonged to Carabidae (51\%), Staphylinidae (25\%) or Araneae (20\%). Most non-predatory taxa were Myriapoda (2,317 individuals) and elongate Collembola (1,442 individuals). Only a few significant differences in arthropod density/activity were found (Table 2). Carabidae counts were significantly higher in the conventional treatment than in the glyphosate treatment $(P \leq 0.05, d . f .=1,4)$ only in the first year and significant differences were maintained when records of grasses and dicotyledons were introduced as covariates $(P \leq 0.05, d . f .=1,4)$. By contrast, Myriapoda were significantly higher in the glyphosate treatment and also only in the first year $(P \leq 0.05, d . f .=1,4)$, but the difference disappeared in the analysis of covariance $(P>0.05, d . f .=1,4)$.

Table 2. Mean ( \pm S.E.) of number of individuals per plant of different arthropod taxa recorded in pitfall traps and probabilities in the one-way ANOVA $\left(d_{\text {. } f .}=1,6\right)$ and one-way ANCOVA when number of monocotyledonous and dicotyledonous weeds were the covariates $(d . f .=1,4)$

\begin{tabular}{|c|c|c|c|c|c|c|}
\hline \multirow{2}{*}{ Taxon } & \multicolumn{2}{|c|}{ Herbicide treatment } & \multirow{2}{*}{$\begin{array}{c}\text { ANOVA }(P) \\
\text { Treatment }\end{array}$} & \multicolumn{3}{|c|}{$\operatorname{ANCOVA}(P)$} \\
\hline & Conventional & Glyphosate & & Monocotyledons & Dicotyledons & Treatment \\
\hline \multicolumn{7}{|c|}{ Year 1} \\
\hline \multicolumn{7}{|l|}{ Detritivores } \\
\hline Myriapoda & $3.37 \pm 1.60$ & $8.57 \pm 2.56$ & 0.022 & 0.039 & 0.321 & 0.627 \\
\hline Collembola & $0.00 \pm 0.00$ & $0.00 \pm 0.00$ & - & - & - & - \\
\hline \multicolumn{7}{|l|}{ Predators } \\
\hline Araneae & $6.67 \pm 1.22$ & $5.66 \pm 1.92$ & 0.351 & 0.374 & 0.645 & 0.553 \\
\hline Dermaptera & $0.93 \pm 0.51$ & $1.24 \pm 0.82$ & 0.697 & 0.391 & 0.976 & 0.135 \\
\hline Carabidae & $17.95 \pm 8.49$ & $6.03 \pm 1.70$ & 0.017 & 0.013 & 0.530 & 0.032 \\
\hline Staphylinidae & $2.72 \pm 1.26$ & $2.32 \pm 0.50$ & 0.799 & 0.758 & 0.561 & 0.791 \\
\hline Total predators & $28.26 \pm 8.38$ & $15.26 \pm 1.42$ & 0.016 & 0.020 & 0.684 & 0.057 \\
\hline \multicolumn{7}{|c|}{ Year 2} \\
\hline \multicolumn{7}{|l|}{ Detritivores } \\
\hline Myriapoda & $53.46 \pm 33.04$ & $50.60 \pm 23.20$ & 0.997 & 0.868 & 0.627 & 0.883 \\
\hline Collembola & $35.02 \pm 31.89$ & $24.69 \pm 19.44$ & 0.560 & 0.869 & 0.544 & 0.844 \\
\hline \multicolumn{7}{|l|}{ Predators } \\
\hline Araneae & $4.98 \pm 1.34$ & $4.75 \pm 1.79$ & 0.757 & 0.705 & 0.933 & 0.956 \\
\hline Dermaptera & $0.47 \pm 0.22$ & $0.34 \pm 0.35$ & 0.385 & 0.277 & 0.623 & 0.692 \\
\hline
\end{tabular}




\begin{tabular}{|c|c|c|c|c|c|c|}
\hline Carabidae & $19.40 \pm 6.44$ & $12.85 \pm 5.91$ & 0.203 & 0.056 & 0.311 & 0.435 \\
\hline Staphylinidae & $6.00 \pm 1.12$ & $4.69 \pm 1.08$ & 0.128 & 0.504 & 0.676 & 0.272 \\
\hline Total predators & $30.85 \pm 6.66$ & $22.62 \pm 7.55$ & 0.151 & 0.081 & 0.462 & 0.351 \\
\hline \multicolumn{7}{|c|}{ Year 3} \\
\hline \multicolumn{7}{|l|}{ Detritivores } \\
\hline Myriapoda & $40.39 \pm 32.40$ & $36.70 \pm 24.06$ & 0.888 & 0.224 & 0.623 & 0.705 \\
\hline Collembola & $32.06 \pm 9.46$ & $28.40 \pm 7.97$ & 0.608 & 0.709 & 0.646 & 0.219 \\
\hline \multicolumn{7}{|l|}{ Predators } \\
\hline Araneae & $7.49 \pm 1.49$ & $8.56 \pm 3.18$ & 0.740 & 0.250 & 0.906 & 0.609 \\
\hline Dermaptera & $1.02 \pm 0.59$ & $1.58 \pm 0.71$ & 0.288 & 0.590 & 0.645 & 0.592 \\
\hline Carabidae & $23.44 \pm 5.50$ & $16.60 \pm 5.16$ & 0.150 & 0.798 & 0.696 & 0.190 \\
\hline Staphylinidae & $15.51 \pm 3.79$ & $15.85 \pm 3.20$ & 0.874 & 0.143 & 0.430 & 0.082 \\
\hline Total predators & $47.45 \pm 8.94$ & $42.58 \pm 7.05$ & 0.464 & 0.917 & 0.712 & 0.613 \\
\hline
\end{tabular}

The whole group of parasitoids caught in yellow sticky traps included 5,115 individuals and most of them (75\%) were Mymaridae, whereas other Chalcidoidea accounted for $19 \%$, Braconidae $4 \%$ and Ichneumonidae $1 \%$. Herbivores were composed of Cicadellidae $(13,524$ individuals), Fulgoroidea $(1,860)$, and Aphididae $(4616)$. Thysanoptera $(22,346)$ included predatory and phytophagous species which could not be distinguished during the trap counting. Chloropidae $(2,947)$ and Muscoidea (572) and a small number of Coccinellidae and Orius spp. were also caught on yellow sticky traps. Only three taxa, Cicadellidae, Thysanoptera, and Mymaridae, showed significantly different catches according to the herbicide treatment and all the significant differences were recorded in the first year $(P \leq 0.05, d . f .=1,6)$, when leafhoppers and mymarids were more abundant in glyphosate-treated plots and thrips were more abundant in conventional herbicide treatment (Table 3). As recorded in the counts on plants, in all three taxa between-treatment differences disappeared when the number of grasses and dicotyledons was introduced in the analysis as a covariate $(P>0.05, d . f .=1,4$ for the three taxa), (Table 3). By contrast, Orius spp. counts were significantly higher only when the covariate of number of grasses and dicotyledons was introduced into the analysis $(P \leq 0.05, d . f .=1,4)$. The remaining herbivores, predators and parasitoids recorded on yellow sticky traps showed no significant differences between the two types of herbicide regime.

Table 3. Mean ( \pm S.E.) number of individuals per plant of different arthropod taxa recorded on yellow sticky traps and probabilities in the one-way ANOVA $(d . f .=1,6)$ and one-way ANCOVA when number of monocotyledonous and dicotyledonous weeds were the covariates $(d . f .=1,4)$

\begin{tabular}{|c|c|c|c|c|c|c|}
\hline \multirow{2}{*}{ Taxon } & \multicolumn{2}{|c|}{ Herbicide treatment } & \multirow{2}{*}{$\begin{array}{c}\text { ANOVA }(P) \\
\text { Treatment }\end{array}$} & \multicolumn{3}{|c|}{$\operatorname{ANCOVA}(P)$} \\
\hline & Conventional & Glyphosate & & Monocotyledons & Dicotyledons & Treatment \\
\hline \multicolumn{7}{|c|}{ Year 1} \\
\hline \multicolumn{7}{|l|}{ Herbivores } \\
\hline Aphididae & $9.42 \pm 2.14$ & $9.30 \pm 2.00$ & 0.962 & 0.904 & 0.432 & 0.376 \\
\hline Cicadellidae & $153.37 \pm 26.67$ & $213.93 \pm 35.74$ & 0.031 & 0.006 & 0.090 & 0.714 \\
\hline Fulgoroidea & $32.25 \pm 6.04$ & $24.45 \pm 5.02$ & 0.111 & 0.185 & 0.989 & 0.844 \\
\hline Thysanoptera & $300.00 \pm 58.77$ & $221.31 \pm 39.54$ & 0.053 & 0.078 & 0.057 & 0.959 \\
\hline \multicolumn{7}{|l|}{ Predators } \\
\hline Orius spp. & $7.25 \pm 1.17$ & $6.50 \pm 0.66$ & 0.303 & 0.229 & 0.242 & 0.037 \\
\hline Coccinellidae & $0.63 \pm 0.19$ & $0.87 \pm 0.40$ & 0.390 & 0.711 & 0.092 & 0.380 \\
\hline \multicolumn{7}{|l|}{ Parasitoids } \\
\hline Ichneumonidae & $1.77 \pm 0.40$ & $1.51 \pm 0.47$ & 0.405 & 0.618 & 0.952 & 0.181 \\
\hline Braconidae & $6.86 \pm 7.21$ & $7.85 \pm 5.95$ & 0.575 & 0.580 & 0.403 & 0.366 \\
\hline Chalcidoidea & $25.22 \pm 23.60$ & $8.77 \pm 0.74$ & 0.081 & 0.106 & 0.083 & 0.666 \\
\hline
\end{tabular}




\begin{tabular}{|c|c|c|c|c|c|c|}
\hline Mymaridae & $43.71 \pm 12.64$ & $83.18 \pm 35.73$ & 0.058 & 0.027 & 0.305 & 0.732 \\
\hline \multicolumn{7}{|l|}{ Detritivores } \\
\hline Muscoidea & $6.43 \pm 2.09$ & $4.68 \pm 1.15$ & 0.226 & 0.015 & 0.016 & 0.966 \\
\hline \multirow[t]{2}{*}{ Chloropidae } & $40.64 \pm 7.02$ & $44.68 \pm 13.36$ & 0.717 & 0.927 & 0.145 & 0.717 \\
\hline & & & Year 2 & & & \\
\hline \multicolumn{7}{|l|}{ Herbivores } \\
\hline Aphididae & $5.81 \pm 0.54$ & $6.12 \pm 1.27$ & 0.746 & 0.287 & 0.183 & 0.192 \\
\hline Cicadellidae & $195.15 \pm 46.02$ & $165.63 \pm 40.40$ & 0.379 & 0.466 & 0.921 & 0.948 \\
\hline Fulgoroidea & $26.67 \pm 0.84$ & $27.17 \pm 6.85$ & 0.960 & 0.728 & 0.381 & 0.575 \\
\hline Thysanoptera & $206.60 \pm 13.92$ & $230.01 \pm 29.18$ & 0.199 & 0.191 & 0.885 & 0.724 \\
\hline \multicolumn{7}{|l|}{ Predators } \\
\hline Orius spp. & $2.86 \pm 0.26$ & $3.09 \pm 0.45$ & 0.404 & 0.411 & 0.636 & 0.788 \\
\hline Coccinellidae & $1.88 \pm 0.65$ & $1.41 \pm 0.44$ & 0.282 & 0.110 & 0.270 & 0.240 \\
\hline \multicolumn{7}{|l|}{ Parasitoids } \\
\hline Ichneumonidae & $0.42 \pm 0.18$ & $0.38 \pm 0.18$ & 0.700 & 0.731 & 0.944 & 0.968 \\
\hline Braconidae & $1.02 \pm 0.22$ & $1.15 \pm 0.34$ & 0.607 & 0.486 & 0.504 & 0.688 \\
\hline Chalcidoidea & $9.27 \pm 1.88$ & $9.12 \pm 1.14$ & 0.968 & 0.963 & 0.643 & 0.762 \\
\hline Mymaridae & $25.16 \pm 2.44$ & $23.56 \pm 3.61$ & 0.462 & 0.804 & 0.945 & 0.254 \\
\hline \multicolumn{7}{|l|}{ Detritivores } \\
\hline Muscoidea & $8.77 \pm 1.23$ & $7.98 \pm 1.45$ & 0.447 & 0.696 & 0.791 & 0.481 \\
\hline \multirow[t]{2}{*}{ Chloropidae } & $52.21 \pm 2.39$ & $56.54 \pm 5.54$ & 0.206 & 0.303 & 0.933 & 0.868 \\
\hline & & & Year 3 & & & \\
\hline \multicolumn{7}{|l|}{ Herbivores } \\
\hline Aphididae & $3.27 \pm 0.40$ & $4.55 \pm 2.19$ & 0.400 & 0.425 & 0.344 & 0.304 \\
\hline Cicadellidae & $223.29 \pm 99.63$ & $175.65 \pm 64.13$ & 0.425 & 0.721 & 0.766 & 0.647 \\
\hline Fulgoroidea & $22.83 \pm 6.02$ & $21.85 \pm 2.30$ & 0.818 & 0.307 & 0.711 & 0.849 \\
\hline Thysanoptera & $362.46 \pm 17.36$ & $541.71 \pm 240.82$ & 0.220 & 0.461 & 0.278 & 0.145 \\
\hline \multicolumn{7}{|l|}{ Predators } \\
\hline Orius spp. & $1.61 \pm 0.35$ & $2.51 \pm 1.17$ & 0.251 & 0.852 & 0.481 & 0.300 \\
\hline Coccinellidae & $1.86 \pm 1.04$ & $1.45 \pm 0.41$ & 0.660 & 0.686 & 0.869 & 0.723 \\
\hline \multicolumn{7}{|l|}{ Parasitoids } \\
\hline Ichneumonidae & $0.31 \pm 0.25$ & $0.25 \pm 0.17$ & - & - & - & - \\
\hline Braconidae & $0.81 \pm 0.13$ & $0.63 \pm 0.15$ & 0.108 & 0.308 & 0.807 & 0.098 \\
\hline Chalcidoidea & $12.83 \pm 3.47$ & $17.67 \pm 9.22$ & 0.429 & 0.911 & 0.884 & 0.359 \\
\hline Mymaridae & $91.07 \pm 33.66$ & $53.71 \pm 9.15$ & 0.087 & 0.918 & 0.205 & 0.215 \\
\hline \multicolumn{7}{|l|}{ Detritivores } \\
\hline Muscoidea & $9.43 \pm 2.20$ & $10.26 \pm 20.01$ & 0.578 & 0.325 & 0.850 & 0.186 \\
\hline Chloropidae & $27.54 \pm 5.06$ & $23.95 \pm 7.02$ & 0.403 & 0.913 & 0.610 & 0.485 \\
\hline
\end{tabular}

\section{Discussion}

Effects of GMHT crops on arthropods may result directly from the toxic effect of broad-spectrum herbicides or the deleterious consequences of the transgenic trait or its products, but they may also be indirectly mediated via plant food resources or habitat modification (Marshall et al., 2001). Only the third pathway is evaluated in the present study. It was not possible to measure any possible effects of the transgenic trait on arthropods as the field was sown with the same GMHT variety in the three years; a direct effect of the broad-spectrum herbicide in comparison with the pre-emergence herbicide treatment was not likely to occur according to most of the records 
in the literature. Only in a few cases have lethal and sublethal effects of broad-spectrum herbicides on natural enemies been recorded (Franz et al., 1997; Ahn et al., 2001; Michalková \& Pekár, 2009; Schneider et al., 2009; Evans et al., 2010).

Andow (1991) attempted to describe relationships between abundance of weeds and response of arthropods, predicting fewer arthropod pest outbreaks in polycultures (spatially intimate mixtures of different plant species with maximum temporal overlap) than in monocultures (the corresponding bare-ground single-crop fields). However, several reported situations contradict the general pattern that he proposed. Availability of GMHT crops offers a good way to test the validity of this general pattern in several crops, geographical localities and weed management practices. Among field trials carried out to measure impacts of GMHT crops on weed flora and higher trophic levels, the British Farm Scale Evaluations gave a good comparison in three crop systems throughout the UK: beet, maize and spring oilseed rape. Hawes et al. (2003) provide a synthetic view of results obtained in these evaluations by analysing whether trends in changes of the different functional groups of arthropods are driven by differences in weed populations. They conclude that there is a positive relationship between availability of resources and consumers, showing the greatest effect in the most sedentary and host-specialist herbivores and the least effect in mobile generalists. Positive relationships between weed abundance and numbers of arthropods were also found by Brooks et al. (2003) in soil-surface-active invertebrates, and only in some epigeal and aerial arthropod taxa by Haughton et al. (2003). A similar conclusion was reached by Smith et al. (2008), who analysed whether changes in weed flora composition might lead to changes in the composition of invertebrate species; they observed changes in the latter driven by alterations in the former but hypothesized that changes may be buffered by the effect of functional redundancy, crop and dispersal.

In a preliminary study carried out to identify the most responsive arthropods to the alteration of weed abundance and composition resulting from the application of glyphosate on GMHT maize in comparison with herbicide-untreated plots (Albajes et al., 2009), authors found that the direction of changes in response to the high differences in weed infestations differed according to the taxon; maize specific leafhoppers and aphids and generalist predators such as Orius spp. and Araneae were more abundant on treated plots with fewer weeds, whereas phytophagous thrips were less abundant on these plots. By contrast, soil-dwelling generalist predators such as Carabidae and Araneae were more abundant on untreated plots than on glyphosate-treated plants in pitfall trap counts. Parasitoids also showed different tendencies in different taxa recorded on yellow sticky traps.

In the work reported herein, differences in arthropods were reduced as the weed infestation differences between the two plots declined over the three years when glyphosate $v s$. conventional treatment were applied on the same plots. In visual counts significant differences were found in leafhoppers, aphids, Orius spp., Araneae and Coccinellidae but only in the first of the three years, when weed infestation was considerably higher in conventional treatment, particularly in grasses. In the second year the differences were lower but still significant, and in the third year there were no differences. These differences in Cicadellidae and Orius spp. densities on plants were discussed by Albajes et al. (2011), who attributed them to crop plant apparency (Cicadellidae) and availability of different prey (Cicadellidae) for Orius, a conclusion also supported by previous results analysed in Albajes et al. (2009). A similar explanation may be applied to Araneae, also generalist predators with leafhoppers as the potential prey (Lang et al., 1999), which showed similar trends to those of Orius spp. The fact that, for most taxa with different counts in conventional vs. glyphosate plots, differences were no longer significant when weed counts were used as a covariate in the ANCOVA supports the hypothesis that alteration of weed abundance is the main cause of changes in herbivore densities on plants. These differences in herbivore insect abundance could explain the differences in the numbers of generalist predators, which would take advantage of the early abundant colonization of maize plants by Cicadellidae in poorly weed-covered fields to build higher populations during the season, enhancing the biological control functions of these arthropods, as hypothesized by Albajes et al. (2011) for Orius spp. and now confirmed for Araneae. Such a mechanism could also account for the results for Aphididae and aphidophagous coccinellids.

Opposite results were obtained for soil-dwelling predators. Carabidae counts were higher on conventional-treated plots but differences were significant only in the first year, when the differences in numbers of weeds in the two types of herbicide treatment were much higher than in the other two years. It is known that Carabidae include omnivorous predators that are able to eat seeds in addition to strictly carnivorous species (Kotze et al., 2011). A higher availability of seeds on conventional-treated plots, especially in the first year, could have favoured the seed-eating species. Most species recorded (> 90\%) were carnivores although a particularly abundant species, Pseudophonus rufipes (De Geer), may behave as an omnivorous predator and consume a certain number of seeds (Kromp, 1999). Another explanation for the higher records of carabids on weedy plots was the higher availability 
of prey such as Collembola on glyphosate-treated plots than on herbicide-untreated plots (Albajes et al., 2009); here, however, with less weed infestation differences between plots, Collembola and other detritivore taxa showed no significant differences and cannot explain differences in soil-dwelling predators, as other authors have argued (Settle et al., 1996; Marcussen et al., 1999; Bilde et al., 2000; Halaj \& Wise, 2002; Prasifka et al., 2006). Independently of the feeding behaviour, differences in carabids seem to be mainly caused by the weediness of plots, as significant differences disappear when weed abundance is introduced as a covariate in the analysis.

Differences recorded in yellow sticky traps were only significant in the first year, when there were more differences in weeds, as observed in visual counts. Moreover, significance of these differences in arthropods was mainly due to the abundance of weeds, as was also concluded for some arthropods recorded in visual counts. Furthermore, numbers of leafhoppers were higher in much less weedy plots, as recorded in visual counts; a lower crop apparency of weedy crops for herbivore colonizers has been signalled as a mechanism explaining less colonization by some herbivores (Root, 1973). A lower colonization of weedy plots has also been observed in the potato leafhopper, Empoasca fabae (Harris), in soybeans (Buckelew et al., 2000), although this association may be related to the effects of weeds on crop plant height or to the different soil coverage by weeds (Lam \& Pedigo, 1998). As hypothesized by Albajes et al. (2011), the much higher number of leafhoppers in glyphosate-treated plots could explain the concomitant greater abundance of their common parasitoids, mymarids, on these plots (Gauld \& Bolton, 1988). It is more difficult to explain the higher abundance of total Thysanoptera on conventional-treated plots because this taxon includes both herbivore and predatory species, so thrips feeding on weeds could be caught in greater amounts on weedy plots. The fact that there were no more herbivore or predatory thrips recorded on crop plants in visual counts could support this hypothesis.

In summary, changes in weed management resulting from the deployment of GMHT maize may alter the abundance and composition of weed flora and consequently the abundance of arthropod taxa, but no general pattern has been detected. The direction of changes in arthropods varies according to the arthropod taxon and the intensity of the weed changes. Low soil coverage by weeds leads to enhanced crop plant colonization by homopterans and higher abundance of generalist predators, but this difference is only significant when the abundance of weeds is greatly impacted by treatment with broad-spectrum herbicides. On the other hand, soil-dwelling carabid beetles are more responsive to changes in weed abundance and tend to decrease when soil coverage by weeds diminishes. Major changes in insect hosts also lead to changes in the numbers of associated parasitoids. Studies like this, that aimed at detecting effects of GMHT crops on non-target organisms, show general tendencies but a more precise study of relationships between specific weeds, their herbivore insects and their natural enemies should be performed in order to predict specific changes in agrosystem biocenosis with greater precision.

\section{References}

Ahn, Y. J., Kim, K. J., \& Yoo, J. K. (2001). Toxicity of the herbicide glufosinate-ammonium to predatory insects and mites of Tetranychus urticae (Acari: Tetranychidae) under laboratory conditions. Journal of Economic Entomology, 94, 157-161. http://dx.doi.org/10.1603/0022-0493-94.1.157

Albajes, R., Lumbierres, B., \& Pons, X. (2009). Responsiveness of arthropod herbivores and their natural enemies to modified weed management in corn. Environmental Entomology, 38, 944-954. http://dx.doi.org/10.1603/022.038.0349

Albajes , R., Lumbierres, B., \& Pons, X. (2011). Two heteropteran predators in relation to weed management in herbicide-tolerant corn. Biological Control, 59, 30-36. http://dx.doi.org/10.1016/j.biocontrol.2011.03.008

Altieri, M. A. (1999). The ecological role of biodiversity in agroecosystems. Agriculture, Ecosystems \& Environment, 74, 19-31. http://dx.doi.org/10.1016/S0167-8809(99)00028-6

Andow, D. A. (1991). Vegetational diversity and arthropod population response. Annual Review of Entomology, 36, 561-586. http://dx.doi.org/10.1146/annurev.en.36.010191.003021

Andow, D. A., \& Risch, S. J. (1985). Predation in diversified agroecosystems: relations between a coccinellid predator Coleomegilla maculata and its food. Journal of Applied Ecology, 22, 357-372. http://dx.doi.org/10.1146/annurev.en.36.010191.003021

Bigler, F., \& Albajes, R. (2011). Indirect effects of genetically modified herbicide tolerant crops on biodiversity and ecosystem services: The biological control example. Journal of Consumer Protection and Food Safety, 6, 79-84.

Bilde, T., Axelsen, J. A., \& Toft, S. (2000). The value of Collembola from agricultural soils as food for a $\begin{array}{lllll}\text { generalist } & \text { Journal of }\end{array}$ 
http://dx.doi.org/10.1046/j.1365-2664.2000.00527.x

Bradley, P. R., Johnson, W. G., Hart, S. E., Buesinger, M. L., \& Massey, R. E. (2000). Economics of weed management in glufosinate-resistant corn (Zea mays L.). Weed Technology, 14, $495-501$. http://dx.doi.org/10.1614/0890-037X(2000)014\%5B0495:EOWMIG\%5D2.0.CO;2

Brooks, D. R., Bohan, D. A., Champion, G. T., Haughton, A. J., Hawes, C., Heard, M. S., ... Walker, M. J. (2003). Invertebrate responses to the management of genetically modified herbicide-tolerant and conventional spring crops. I. Soil-surface-active invertebrates. Philosophical Transactions of the Royal Society, London B, Biological Sciences, 358, 1847-1862. http://dx.doi.org/10.1098/rstb.2003.1407

Buckelew, L. D., Pedigo, L. P., Mero, H. M., Owen, M. D. K., \& Tylka, G. L. (2000). Effects of weed management systems on canopy insects in herbicide-resistant soybeans. Journal of Economic Entomology, 93, 1437-1443. http://dx.doi.org/10.1603/0022-0493-93.5.1437

Comas, J., Lumbierres, B., Pons, X., \& Albajes, R. (2013). Ex-ante determination of the capacity of field tests to detect effects of genetically modified corn on nontarget arthropods optimizing the capacity of field trials to detect the effect of genetically modified maize on non-target organisms through longitudinal sampling. Journal of Economic Entomology, 106, 1659-1668. http://dx.doi.org/10.1603/EC12508

Dewar, A. M. (2009). Weed control in glyphosate-tolerant maize in Europe. Pest Management Science, 65, 1047-1058. http://dx.doi.org/10.1002/ps.1806

EFSA (European Food Safety Authority). (2010). Scientific opinion on statistical considerations for the safety evaluation of GMOs. EFSA Panel on Genetically Modified Organisms (GMO). EFSA Journal 20108 , 1250 .

Evans, S. C., Shaw, E. M., \& Rypstra, A. L. (2010). Exposure to a glyphosate-based herbicide affects agrobiont predatory arthropod behavior and long-term survival. Ecotoxicology, 19, 1249-1257. http://dx.doi.org/10.1007/s10646-010-0509-9

Franz, J. E., Mao, M. K., \& Sikorski, J. A. (1997). Glyphosate: a unique and global herbicide. ACS Monograph n. 189. Washington DC: American Chemical Society.

Gianoli, E., Ramos, I., Alfaro-Tapia, A., Valdez, Y., Echegaray, E. R., \& Yábar, E. (2006). Benefits of a maize-bean-weeds mixed cropping system in Urubamba Valley, Peruvian Andes. International Journal of Pest Management, 52, 283-289. http://dx.doi.org/10.1080/09670870600796722

Halaj, J., \& Wise, D. H. (2002). Impact of a detrital subsidy on trophic cascades in a terrestrial grazing food web. Ecology, 83, 3141-3151. http://dx.doi.org/10.1890/0012-9658(2002)083\%5B3141:IOADSO\%5D2.0.CO;2

Haughton, A. J., Champion, G. T., Hawes, C., Heard, M. S., Brooks, D. R., Bohan, D. A., ... Walker, M. J. (2003). Invertebrate responses to the management of genetically modified herbicide-tolerant and conventional spring crops. II. Within-field epigeal and aerial arthropods. Philosophical Transactions of the Royal Society, London B, Biological Sciences, 358, 1863-1877. http://dx.doi.org/10.1098/rstb.2003.1408

Hawes, C., Haughton, A. J., Osborne, J. L., Roy, D. B., Clark, S. J., Perry, J. N., ... Squire, G. R. (2003). Responses of plants and invertebrate trophic groups to contrasting herbicide regimes in the farm scale evaluations of genetically modified herbicide-tolerant crops. Philosophical Transactions of the Royal Society, London B, Biological Sciences, 358, 1899-1913. http://dx.doi.org/10.1098/rstb.2003.1406

Heard, M. S., Hawes, C. T., Champion, G. T., Clark, S. J., Firbank, L. G., Haughton, A. J., ... Hill, M. I. (2003). Weeds in fields with contrasting conventional and genetically modified herbicide-tolerant crops. I. Effects on abundance and diversity. Philosophical Transactions of the Royal Society, London B, Biological Sciences, 358, 1819-1932. http://dx.doi.org/10.1098/rstb.2003.1402

James, C. (2013). Global status of commercialized biotech/GM crops: 2013. Brief No. 46. Ithaca, NY: ISAAA.

Kotze, D. J., Brandmayr, P., Casale, A., Dauffy-Richard, E., Dekoninck, W., Koivula, M., ... Zetto, T. (2011). Forty years of carabid beetle research in Europe - from taxonomy, biology, ecology and population studies to bioindication, habitat assessment and conservation. ZooKeys, 100, 55-148. http://dx.doi.org/10.3897/zookeys.100.1523

Kromp, B. (1999). Carabid beetles in sustainable agriculture: A review on pest control efficacy, cultivation impacts and enhancement. Agriculture, Ecosystems \& Environment, 74, 187-228. http://dx.doi.org/10.1016/S0167-8809(99)00037-7

Lam, W. F., \& Pedigo, L. P. (1998). Response of soybean insect communities to row width under crop-residue 
management systems. Environmental Entomology, 27, 1069-1079.

Lang, A., Filser, J., \& Henschel, J. R. (1999). Predation by ground beetles and wolf spiders on herbivorous insects in a maize crop. Agriculture, Ecosystems \& Environment, 72, 189-199. http://dx.doi.org/10.1016/S0167-8809(99)00037-7

Lundgren, J. G., Gassmann, A. J., Bernal, J., Duan, J. J., \& Ruberson, J. (2009). Ecological compatibility of GM crops and biological control. Crop Protection, 28, 1017-1030. http://dx.doi.org/10.1016/j.cropro.2009.06.001

Marcussen, B. M., Axelsen, J. A., \& Toft, S. (1999). The value of Isotoma viridis and Folsomia fimetaria (Collembola: Isotomidae) as food for Erigone atra (Araneae: Erigoniddae). Entomologia Experimentalis et Applicata, 92, 29-36.

Marshall, J., Brown, V. K., Boatman, N., Lutman, P., \& Squire, G. R. (2001). The impact of herbicides on weed abundance and biodiversity. Defra PN0940. A report for the UK Pesticides Safety Directorate. Bristol: IACR Long Ashton Research Station.

Michalková, V., \& Pekár, S. (2009). How glyphosate altered the behaviour of agrobiont spiders (Araneae: Lycosidae) and beetles (Coleoptera: Carabidae). Biological Control, 51, 444-449. http://dx.doi.org/10.1016/j.biocontrol.2009.08.003

Norris, R. F., \& Kogan, M. (2000). Interactions between weeds, arthropod pests, and their natural enemies in managed $\quad$ Weed $\quad$ Science, $\quad 48, \quad 94-158$. http://dx.doi.org/10.1614/0043-1745(2000)048\%5B0094:IBWAPA\%5D2.0.CO;2

Penagos, D. I., Magallanes, R., Valle, J., Cisneros, J., Martínez, A. M., Goulson, D., ... Williams, T. (2003). Effect of weeds on insect pests of maize and their natural enemies in southern Mexico. International Journal of Pest Management, 49, 155-161. http://dx.doi.org/10.1080/0967087021000043111

Prasifka, J. R., Schmidt, N. P., Kohler, K. A., O’Neal, M. E., Hellmich, R. L., \& Singer, J. W. (2006). Effects of living mulches on predator abundance and sentinel prey in a corn- soybean- forage rotation. Environmental Entomology, 35 , 1423-1431. http://dx.doi.org/10.1603/0046-225X(2006)35\%5B1423:EOLMOP\%5D2.0.CO;2

R Development Core Team. (2008). R: A language and environment for statistical computing. Vienna, Austria: $\mathrm{R}$ Foundation for Statistical Computing.

Ritchie, S. W., Hanway, J. J., \& Benson, G. O. (1992). How a corn plant develops. Ames, IA: Iowa State University.

Root, R. B. (1973). The organization of a plant-arthropod association in simple and diverse habitats: the fauna of collards, Brassica oleracea. Ecological Monographs, 43, 95-124. http://dx.doi.org/10.2307/1942161

Roy, D. B., Bohan, D. A., Haughton, A. J., Hill, M. O., Osborne, J. L., Clark, S. J., ... Firbank, L. G. (2003). Invertebrates and vegetation of field margins adjacent to crops subject to contrasting herbicide regimes in the farm scale evaluations of genetically modified herbicide-tolerant crops. Philosophical Transactions of the Royal Society, London B, Biological Sciences, 358, 1879-1898. http://dx.doi.org/10.1098/rstb.2003.1404

Schneider, M. I., Sanchez, N., Pineda, S., Chi, H., \& Ronco, A. (2009). Impact of glyphosate on the development, fertility, and demography of Chrysoperla externa (Neuroptera: Chrysopidae): Ecological approach. Chemosphere, 76, 1451-1455. http://dx.doi.org/10.1016/j.chemosphere.2009.05.029

Settle, W. H., Ariawan, H., Astuti, E. T., Cahyana, W., Hakim, A. L., Hindayana, D., \& Lestari, A. S. (1996). Managing tropical rice pests through conservation of generalist natural enemies and alternative prey. Ecology, 77, 1975-1988. http://dx.doi.org/10.2307/2265694

Smith, V., Bohan, D. A., Clark, S. J., Haughton, A. J., Bell, J. R., \& Heard, M. S. (2008). Weed and invertebrate community compositions in arable farmland. Arthropod-Plant Interactions, 2, 21-30. http://dx.doi.org/10.1007/s11829-007-9027-y

\section{Copyrights}

Copyright for this article is retained by the author(s), with first publication rights granted to the journal.

This is an open-access article distributed under the terms and conditions of the Creative Commons Attribution license (http://creativecommons.org/licenses/by/3.0/). 